\title{
miR-139-5p is a regulator of metastatic pathways in breast cancer
}

\author{
KEERTHANA KRISHNAN, ${ }^{1}$ ANITA L. STEPTOE, ${ }^{1}$ HILARY C. MARTIN, ${ }^{1,9}$ DIWAKAR R. PATTABIRAMAN, ${ }^{2}$ \\ KATIA NONES, ${ }^{1}$ NIC WADDELL, ${ }^{1}$ MYTHILY MARIASEGARAM, ${ }^{3}$ PETER T. SIMPSON, ${ }^{3}$ SUNIL R. LAKHANI, ${ }^{3,4,5}$ \\ ALEXANDER VLASSOV, ${ }^{6}$ SEAN M. GRIMMOND, ${ }^{1,8,10}$ and NICOLE CLOONAN ${ }^{1,7,10}$ \\ ${ }^{1}$ Queensland Centre for Medical Genomics, Institute for Molecular Bioscience, University of Queensland, St Lucia, QLD, Australia 4072 \\ ${ }^{2}$ Whitehead Institute for Biomedical Research, Cambridge, Massachusetts 02142, USA \\ ${ }^{3}$ The University of Queensland, UQ Centre for Clinical Research (UQCCR), Herston, QLD, Australia 4029 \\ ${ }^{4}$ The University of Queensland, School of Medicine, Herston, QLD, Australia 4029 \\ ${ }^{5}$ Pathology Queensland, The Royal Brisbane and Women's Hospital, Herston, QLD, Australia 4029 \\ ${ }^{6}$ Life Technologies, Austin, Texas 78744, USA \\ ${ }^{7}$ QIMR Berghofer Medical Research Institute, Genomic Biology Laboratory, Herston, Australia 4006 \\ ${ }^{8}$ Wolfson Wohl Cancer Research Centre, Institute of Cancer Sciences, University of Glasgow, Glasgow, G61 1BD, United Kingdom
}

\begin{abstract}
Metastasis is a complex, multistep process involved in the progression of cancer from a localized primary tissue to distant sites, often characteristic of the more aggressive forms of this disease. Despite being studied in great detail in recent years, the mechanisms that govern this process remain poorly understood. In this study, we identify a novel role for miR-139-5p in the inhibition of breast cancer progression. We highlight its clinical relevance by reviewing miR-139-5p expression across a wide variety of breast cancer subtypes using in-house generated and online data sets to show that it is most frequently lost in invasive tumors. A biotin pull-down approach was then used to identify the mRNA targets of miR-139-5p in the breast cancer cell line MCF7. Functional enrichment analysis of the pulled-down targets showed significant enrichment of genes in pathways previously implicated in breast cancer metastasis $(P<\mathbf{0 . 0 5})$. Further bioinformatic analysis revealed a predicted disruption to the TGF, Wnt, Rho, and MAPK/PI3K signaling cascades, implying a potential role for miR-139-5p in regulating the ability of cells to invade and migrate. To corroborate this finding, using the MDA-MB-231 breast cancer cell line, we show that overexpression of miR-139-5p results in suppression of these cellular phenotypes. Furthermore, we validate the interaction between miR-139-5p and predicted targets involved in these pathways. Collectively, these results suggest a significant functional role for miR-139-5p in breast cancer cell motility and invasion and its potential to be used as a prognostic marker for the aggressive forms of breast cancer.
\end{abstract}

Keywords: biomarker; breast cancer; miRNA

\section{INTRODUCTION}

Breast cancer is the most commonly diagnosed cancer in women and a leading cause of cancer mortality. One of the major determinants of breast cancer mortality is the stage of disease at diagnosis; patients who present with metastatic disease have a 5-year survival rate of 21\% (Cardoso and Castiglione 2009). The progression of primary tumors to metastatic disease is known to involve (1) invasion of extracellular matrix and stromal layers by the tumor cells, (2) intravasation into the bloodstream to travel to a distant or-

\footnotetext{
${ }^{9}$ Present address: Wellcome Trust Centre for Human Genetics, University of Oxford, Oxford OX3 7BN, UK

${ }^{10}$ Corresponding authors

E-mail s.grimmond@uq.edu.au

E-mail nicole.cloonan@qimr.edu.au

Article published online ahead of print. Article and publication date are at http://www.rnajournal.org/cgi/doi/10.1261/rna.042143.113. Freely available online through the RNA Open Access option.
}

gan, (3) extravasation into the parenchyma of distant tissues, and (4) colonization and outgrowth of tumors in the distant site (for review, see Fidler 2003). The molecular mechanisms underlying metastatic migration and invasion are only partially understood, despite several signaling pathways being implicated (Blanco and Kang 2011). Interaction between carcinoma cells and their neighboring stroma has also been shown to play a critical role (Bhowmick et al. 2004).

Recently, miRNAs have also been found to play a key role in metastases (Ma et al. 2007; Valastyan et al. 2009). miRNAs are short noncoding RNAs that suppress target gene activity predominantly through binding to target mRNAs and inhibiting their translation. miRNAs have also been shown to promote target gene degradation (for review, see Fabian et al. 2010; Huntzinger and Izaurralde 2011). Several miRNAs have

(c) 2013 Krishnan et al. This article, published in $R N A$, is available under a Creative Commons License (Attribution-NonCommercial 3.0 Unported), as described at http://creativecommons.org/licenses/by-nc/3.0/. 
causative or correlative links with metastasis. In the case of breast cancer, miR-21 overexpression has been shown to promote metastasis (Asangani et al. 2008; Zhu et al. 2008). miR31 regulates the expression of the key metastatic genes integrin- $\alpha 5$, radixin, and RhoA (Valastyan et al. 2009). miR-200 has also been shown to increase metastatic potential of mammary carcinoma cell lines (Korpal et al. 2011), while other studies have observed an inverse correlation between miR200 expression and tumor invasion and metastasis (Gregory et al. 2008; Korpal et al. 2008). Overexpression of miR-139$5 \mathrm{p}$ was recently shown to correlate with reduced metastatic activity in hepatocellular carcinoma and gastric cancer cells (Bao et al. 2011; Wong et al. 2011; Li et al. 2013) and downregulated in glioblastoma (Li et al. 2013). Furthermore, in patients with invasive squamous cell carcinoma, loss of miR139-5p expression is associated with increased metastatic disease (Mascaux et al. 2009).

Although a strong association between miR-139-5p and metastasis exists, there is little knowledge of the mechanisms by which it contributes to this process or of the gene networks it regulates; the specific pathways that are disrupted are still poorly understood. Only five targets of miR-139-5p have been identified and validated so far: FoxO1 (Hasseine et al. 2009), Rho-kinase2 (Wong et al. 2011), CXCR4 (Bao et al. 2011), RAP1B (Guo et al. 2012), and Type I Insulin-like GF (Shen et al. 2012). However, its role in breast cancer has not been studied so far.

miRNAs have the potential to be oncogenes or tumor suppressors in a given cellular context. Depending on the specific tissues or cancer type they are expressed in, miRNAs achieve functional specificity by targeting a core network of genes that belong to the same pathway. This interaction is highly dependent on the relative abundance of multiple mRNA targets. For instance, miR-17-5p is oncogenic in hepatocellular and colorectal carcinomas (Ma et al. 2012; Shan et al. 2013) and, in contrast, has been shown to have tumor-suppressive properties in cervical cancer cells (Wei et al. 2012). Similarly, miR-182-5p was shown to have oncogenic properties in bladder, ovarian, and breast cancers (Hirata et al. 2012; Liu et al. 2012; Krishnan et al. 2013), whereas it acts as a tumor suppressor in lung cancer (Sun et al. 2010). Given this molecular and context specificity of miRNAs, we wished to explore whether miR-139-5p was a potential oncomir of breast cancer and what the output of its functional repression was, and identify the network of genes possibly regulating its functions in the context of breast cancer.

\section{RESULTS}

\section{miR-139-5p is de-regulated in human triple negative breast cancer samples}

To assess the clinical relevance of miR-139-5p in human breast cancer, we measured its expression in a cohort of breast cancer patient samples $(n=40)$ that included the following molecular subtypes of invasive ductal carcinomas-no special type (IDC-NST): triple negative $(n=18), \operatorname{Her} 2+(n=4), \mathrm{ER}+/$ $\mathrm{PR}+(n=9)$; invasive lobular carcinomas (ILC) $(n=3)$; and normal breast tissue $(n=6)$ (Supplemental Table 1). The expression levels of miR-139-5p were assayed by qRTPCR relative to an endogenous control RNU6B (Fig. 1A). We observe an increase in the levels of miR-139-5p in normal mammary tissue and several subtypes, but the triple negative subtype showed a marked variable pattern where $38 \%$ of the samples had lower expression compared to the normal controls. Since this subtype is heterogeneous at clinical, morphological, and molecular levels, it is possible that the low miR139-5p expressing subgroup is one with a very different prognosis (Cheang et al. 2008), and further studies are warranted to try to validate this. Although the difference in the population average did not reach statistical significance, the loss of miR-139-5p expression may help to identify a new molecular subtype important for the biological understanding of disease and for clinical management within this invasive subgroup of breast cancer.

\section{miR-139-5p is frequently down-regulated in invasive breast carcinoma}

Next, we reviewed miR-139-5p expression in previously published data using TaqMan Low-Density Arrays to analyze 29 breast tumors and 21 normal adjacent controls (RomeroCordoba et al. 2012). This sample cohort included invasive ductal carcinomas $(n=26)$, invasive lobular carcinomas $(n=1)$, invasive mucinous carcinomas (IMC) $(n=1)$, and ductal carcinoma in situ (DCIS) $(n=1)$. Of the IDCs, only five samples were triple negative. As shown in Figure 1B, miR-139-5p is significantly $(P$ value $<0.0001)$ down-regulated in the tumor cohort compared to normal controls. To strengthen the validity of this expression profile, we also looked for changes in expression of known metastasis-associated miRNAs in breast cancer. Importantly, miR-139-5p expression positively correlates with miR-31 $(r=0.44)$ and miR-200b $(r=0.36)$, which are well-characterized anti-metastatic miRNAs in breast cancer (Korpal et al. 2008; Valastyan et al. 2009). This result suggested that miR-139-5p could be another marker for metastatic breast cancer besides the association with triple negative tumors.

To further investigate the expression of miR-139-5p across a larger cohort of patient samples, we chose to analyze a miRNA-seq data set (Farazi et al. 2011) consisting of normal breast tissue $(n=16)$ and various types of breast cancer including: adenoid cystic carcinoma $((n=2)$, apocrine carcinoma $(n=4)$, atypical medullary carcinoma $(n=9)$, metaplastic carcinoma $(n=11)$, mucinous carcinoma $(n=1)$, ductal carcinoma in situ $(n=21)$, and invasive ductal carcinoma $(n=$ 174). Although the adenoid cystic carcinoma, a proportion of apocrine carcinomas, atypical medullary, and metaplastic carcinomas can be classified as basal-like molecular subtypes, they differ in their morphology, aggressiveness, and prognosis 

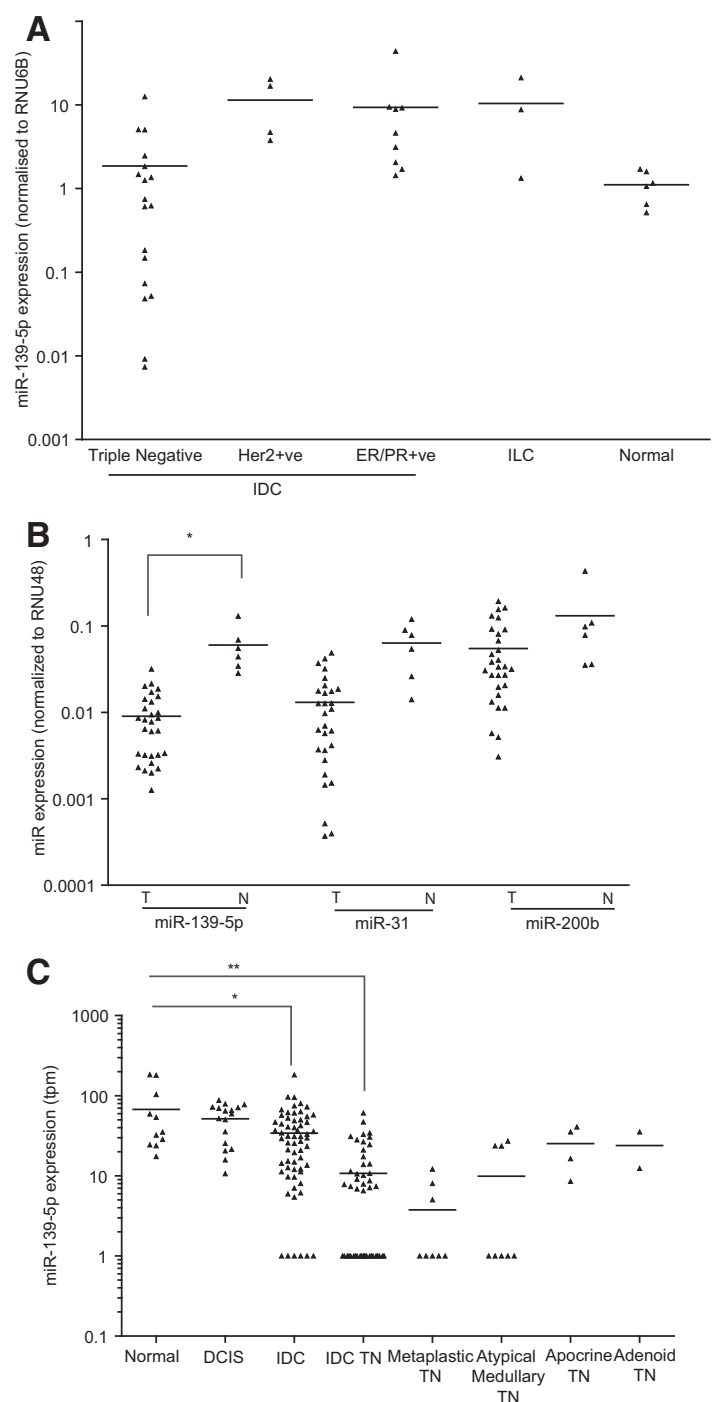

FIGURE 1. Expression analysis of miR-139-5p across tumor subtypes and normal tissue from human breast cancer patient samples. $(A)$ Lines represent the mean of miR-139-5p expression (normalized to RNU6B) across sample subtypes: triple negative $(n=18)$, Her2+ $(n=4)$, $\mathrm{ER}+/ \mathrm{PR}+(n=9)$, invasive lobular carcinomas $(n=3)$, normal breast tissue $(n=6)$. Triangles represent the expression levels for individual patients. (B) Expression of miRNAs in breast cancer as assessed by TaqMan Low Density Arrays (Romero-Cordoba et al. 2012). Lines represent the mean expression of miR-139-5p, alongside well-characterized anti-metastatic miRNAs like miR-31 and miR-200b (normalized to RNU6B) across the sample cohort (comparing tumor versus normal along the $x$-axis). Triangles represent the expression levels for individual patients. Asterisks indicate significant difference between the expression of miR-139-5p in the tumour compared to the adjacent normal tissue ([*] $P<0.0001$, Student's $t$-test). $(C)$ miR-139-5p expression as assessed using miRNA-sequencing from Farazi et al. (2011) across normal breast tissue $(n=16)$ and a panel of breast cancer patient samples of various subtypes, including adenoid cystic carcinoma $(n=2)$, apocrine carcinoma $(n=4)$, atypical medullary carcinoma $(n=9)$, metaplastic carcinoma $(n=11)$, mucinous carcinoma $(n=1)$, ductal carcinoma in situ (DCIS) $(n=21)$, and invasive ductal carcinoma (IDC) $(n=174)$. Lines and scatter plot represent the mean across a subtype and the transcripts per million (tpm) of miR-139-5p in each sequenced sample, respectively. Asterisks indicate significant difference between the expression of miR-139-5p in the specific tumor subtype compared to the normal tissue. $\left({ }^{* *}\right) P<0.0001,\left(^{*}\right) P \sim 0.007$, Student's $t$-test.
(Yerushalmi et al. 2009; Marchio et al. 2010; Park et al. 2010). Metaplastic carcinomas are a heterogeneous group of tumors characterized by the presence of epithelial cells (spindle, squamous) with or without metaplastic elements such as bone, cartilage, and muscle. They are aggressive tumors with a poor prognosis (Park et al. 2010). Medullary carcinoma is a controversial entity defined by Ridolfi and, despite the high grade, is said to have a good prognosis. In contrast, tumors that do not fulfill the criteria for typical medullary carcinomas have been designated as atypical medullary carcinomas (Ridolfi et al. 1977). These are more aggressive and have morphological features and prognosis that overlap with high grade IDC (Ridolfi et al. 1977). Adenoid cystic carcinoma, despite falling into the basal-like category, is an indolent tumor in the breast compared to its salivary gland counterpart. Carcinomas with apocrine differentiation are heterogeneous, and the behavior is dependent on grade and stage (Yerushalmi et al. 2009; Marchio et al. 2010). Interestingly, as shown in Figure 1C, the subtypes that have the worst prognosis and the highest propensity to form distant metastases (metaplastic carcinomas, atypical medullary, and the high grade TN IDCs) exhibit the lowest levels of miR-139-5p expression. Within the IDCs, those patients with a triple negative phenotype show a more significant $(P<0.001)$ down-regulation compared to those that express either ER/PR or Her2 $(P \sim 0.007)$. However, not all triple negative patient samples show a down-regulation of miR-139-5p expression as seen in Figure $1 \mathrm{~A}$ and in some subtypes in Figure 1C, but the common feature among these results is that miR-139-5p is frequently lost in the most aggressive subtypes of breast cancer, suggesting that it may play a key role in the metastatic cascade of breast cancer.

\section{Identification of direct targets of miR-139-5p using a biotinylated miRNA duplex}

It is well established that the function of microRNAs depends on the expression of their targets (Sood et al. 2006) and that the differing expression of these targets in different cellular states can lead to opposing phenotypic outcomes-for example, overexpression of miR-17-5p acts as either an oncogene or a tumor suppressor depending on what tissue it is expressed in (Cloonan et al. 2008). Therefore, it is critical to robustly identify the direct targets of miR-139-5p in breast cancer cells. Given that target prediction programs are noisy and have high false-positive rates (Bentwich 2005; Sood et al. 2006), we resorted to an experimental identification of targets. We used the recently reported miRNA pull-down approach (Cloonan et al. 2011) that involves transfecting synthetic biotinylated miR-139-5p duplexes (Fig. 2A) into cells (in our case, MCF7 cells) and surveying the captured target mRNAs using microarrays. Figure $2 \mathrm{~B}$ shows sample clustering of cells transfected with biotinylated miR-139-5p and the total lysates where total distance between samples indicates similarity, highlighting the reproducibility of the pull- 
A

\begin{tabular}{|c|}
\hline miR-139-5p biotin duplex \\
\hline 5'- UCUACAGUGCACGUGUCUCCAG -Biotin-3' \\
3'- GAAGAUGUCACGUGCACAGAGG -5' \\
\hline
\end{tabular}

B

Sample relations based on 16181 genes with $\mathrm{sd} /$ mean $>0.1$

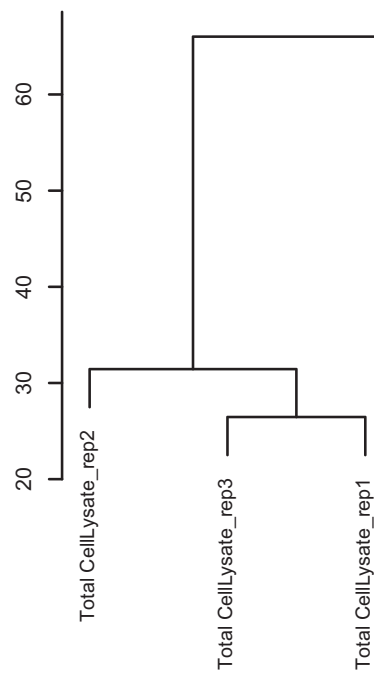

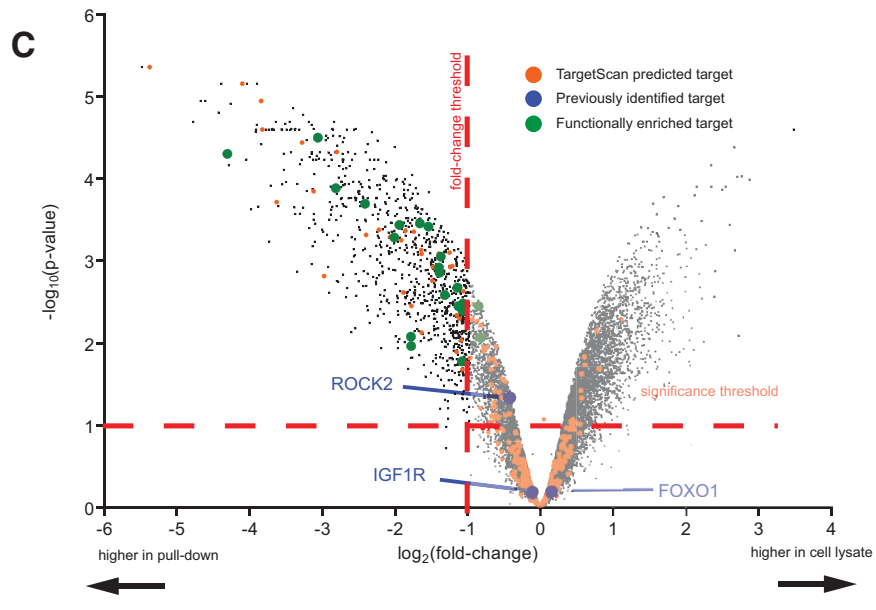

D

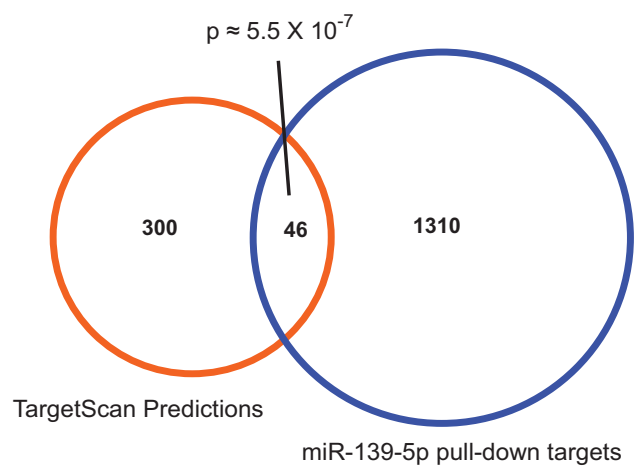

FIGURE 2. Identifying targets of miR-139-5p via biotin pull-down. (A) Sequence and position of biotin in the molecule used to transfect MCF7 cells for the pull-down approach used to identify biologically relevant targets of miR-139-5p. (B) Hierarchical clustering of microarray data was performed using the plotSampleRelations function in the lumi package. Total vertical distance between samples indicates similarity. $(C)$ A "volcano plot" showing the $\log _{2}$-transformed fold-change versus the $\log _{10}$-transformed $P$-value of that fold-change for every gene detected above background in the microarray. Genes highlighted in blue are targets validated by previous studies. Genes highlighted in orange are predicted by TargetScan to be targets of miR139-5p, showing an enrichment of the targets in the pull-downs compared to the controls. Genes highlighted in green have known association with pathways frequently involved in metastasis. $(D)$ Venn diagram showing the overlap of genes between TargetScan predicted targets of miR-139-5p (also expressed above background in HEK293Ts) and biotinylated miR-139-5p pull-down predicted targets. This overlap is significantly more than expected by chance.

down approach between biological replicates. We identified mRNAs significantly enriched in the biotin fraction compared to the input RNA at a 5\% false discovery rate (FDR) threshold, with a fold-change $>2$ (Fig. 2C). Using this approach, 884 probes (targeting 879 genes) were found to be significantly enriched in the pull-down fractions (Supplemental Table 2).

Next, we compared the miR-139-5p pull-down targets to TargetScan predicted targets and saw an overlap between the experimentally determined and the predicted targets which was significantly more than expected by chance $(P \approx$ $5.5 \times 10^{-7}$ ) (Fig. $2 \mathrm{D}$ ), supporting the notion that we are enriching for biologically relevant targets of miR-139-5p. As expected, some targets identified in other pathologies are either not expressed in MCF7 cells (2/5) or do not meet our stringent threshold for target identification (Fig. 2C). Figure 2C highlights (in green) the significantly enriched genes that are associated with the metastatic cascade, specifically in the context of breast cancer. miRNAs regulate cellular processes by concomitant suppression of a network of genes, so we included genes which do not pass our stringent threshold cutoff for target identification, since they belong to closely connected pathways associated with the invasive ability of cancer cells. Together, these results demonstrate that the pull-down has enriched for miR-139-5p's biological targets.

\section{miR-139-5p targets genes involved in pathways associated with metastasis}

A gene set enrichment analysis (GSEA) was performed using ingenuity pathway analysis (IPA) on the miR-139-5p targets significantly enriched in the biotin pull-down. The list of pull-down-enriched 879 genes (Supplemental Table 2) was compared to 10 other random gene lists of the same size to 
confirm specificity. A functional ontology was only considered significant if its $-\log (P$-value $)$ was at least four standard deviations away from the mean $-\log (P$-value $)$ of the 10 random gene lists. Supplemental Table 3 lists all canonical pathways (IPA) showing significant enrichment $(P$-value $<0.05)$ for miR-139-5p pull-down targets. As predicted, several significantly enriched pathways have been previously implicated in metastatic biology (Table 1), with confirmed roles for all but one in breast cancer.

Functional enrichment analysis identified several canonical pathways previously implicated in the metastatic cascade, but the specific mechanism by which miR-139-5p modulates key signaling pathways underlying these processes is still unknown. To explore this, we analyzed the list of significantly enriched targets from the pull-down approach and explored the literature for their known role specifically in cellular processes underlying metastasis, including cell proliferation, migration, and invasion. Shown in Figure 3 are key signaling cascades underlying these processes, with targets of miR$139-5 p$ highlighted in dark gray $\left(\log _{2} \mathrm{FC}>1\right)$ and light gray $\left(\log _{2}\right.$ FC >0.5) and targets previously validated in other studies. The signaling molecules identified from this analysis were found to be part of three major pathways: (1) Wnt signaling which consists of canonical and noncanonical arms, depending on the ligand; canonical Wnt signaling occurs upon recruitment of $\beta$-catenin to the nucleus (Clevers and Nusse 2012), whereas the noncanonical streams work through downstream activation of molecules such as PRKC and RHO (Schlessinger et al. 2009), both of which are known players in breast cancer progression (Scheel et al. 2011); (2) receptor tyrosine kinases (RTK) signal through several pathways including RAS-MAPK and PI3 kinase, activating several downstream signal transducers, such as RAF1 and RAC1, and transcription factors such as MAPK3/1 (ERK1/2), NFKB, CEBPB, and TWIST1, all of which play important roles in breast cancer progression (Chaudhary et al. 2000; Bundy and Sealy 2003; Buchholz et al. 2005; Kim et al. 2008; Hong et al. 2011); (3) TGFB signaling which plays an important role in breast cancer (Buck and Knabbe 2006), epithelial to mesenchymal transition (EMT) (Zavadil and Bottinger 2005), and breast cancer metastasis (Padua et al. 2008). Interestingly, TGFB also cross-talks with several other pathways, including estrogen receptor signaling (Matsuda et al. 2001), which have also been identified as miR-139-5p targets from our analyses. Also interestingly, proteins underlying this pathway were identified to be potentially regulated by miR139-5p using target prediction software (Lee et al. 2013).

This analysis outlines the complex set of targets that appear to be regulated by miR-139-5p, a major proportion of them being involved in tumor progression and metastasis. It suggests possible mechanistic targets of miR-139-5p in the regulation of metastasis, warranting further functional characterization of its role in suppressing these functional phenotypes.

\section{miR-139-5p does not alter proliferation or DNA profile in MDA-MB-231 cells}

The pathways analysis suggested a role for miR-139-5p in promoting breast cancer metastasis. To confirm its relevance in processes underlying malignancy of tumor cells, we undertook a series of cell-based assays. Previous studies have reported a prognostic role for cell proliferation in the metastatic ability of tumors (Maeda et al. 1996; Panizo-Santos et al. 2000). Moreover, cell proliferation has been reported to be altered by miR-139-5p in human colorectal carcinoma through regulating the expression of RAP1B (Guo et al. 2012).

To test whether this phenotype was relevant in breast cancer, we generated four stable cell lines with inducible expression of miR-139-5p in MDA-MB-231 cells, a well-characterized invasive breast cancer cell line. Doxycycline-induced expression of miR-139-5p for each cell line was confirmed using TaqMan real time PCR (Fig. 4A). The four stable cell lines show between 20 - and 200-fold higher expression of miR-139$5 \mathrm{p}$ in the presence of $1000 \mathrm{ng} / \mathrm{mL}$ doxycycline, which is also comparable to the difference in expression seen between normal breast tissues relative to tumor patient samples (Fig. 1C). Sequencing the small RNA population of the MDA-MB-231

TABLE 1. miR-139-5p target enriched canonical pathways and their association with tumor progression

\begin{tabular}{|c|c|c|c|c|}
\hline Pathway & $P$-value & $\begin{array}{l}\text { Associated with } \\
\text { metastasis? }\end{array}$ & Cancer type & References \\
\hline Protein ubiquitination pathway & $1.00 \times 10^{-5}$ & Yes & Breast & Kim et al. (2011) \\
\hline ERK5 signaling & $2.95 \times 10^{-5}$ & Yes & Breast, prostate & Cronan et al. (2011); Ramsay et al. (2011) \\
\hline Aminoacyl-tRNA biosynthesis & $1.95 \times 10^{-4}$ & Maybe (tumorigenesis) & Lung, colon & Kim et al. (2011) \\
\hline $\mathrm{N}$-Glycan biosynthesis & $2.90 \times 10^{-4}$ & Yes & Breast & Lau and Dennis (2008) \\
\hline $\begin{array}{l}\text { Glucocorticoid receptor } \\
\text { signaling }\end{array}$ & $3.55 \times 10^{-4}$ & Maybe (tumorigenesis) & Breast & Moutsatsou and Papavassiliou (2008) \\
\hline NGF signaling & $3.90 \times 10^{-4}$ & Yes & Breast & Adriaenssens et al. (2008) \\
\hline $\begin{array}{l}\text { Xenobiotic metabolism } \\
\text { signaling }\end{array}$ & $5.80 \times 10^{-4}$ & Maybe (tumorigenesis) & Breast & Aust et al. (2005); Naushad et al. (2011) \\
\hline HGF signaling & $6.50 \times 10^{-4}$ & Yes & Breast, melanoma & Maroni et al. (2007); Previdi et al. (2010) \\
\hline PI3K/AKT signaling & $1.15 \times 10^{-3}$ & Yes & Breast, lung, thyroid & Smirnova et al. (2012); Xue et al. (2012) \\
\hline
\end{tabular}




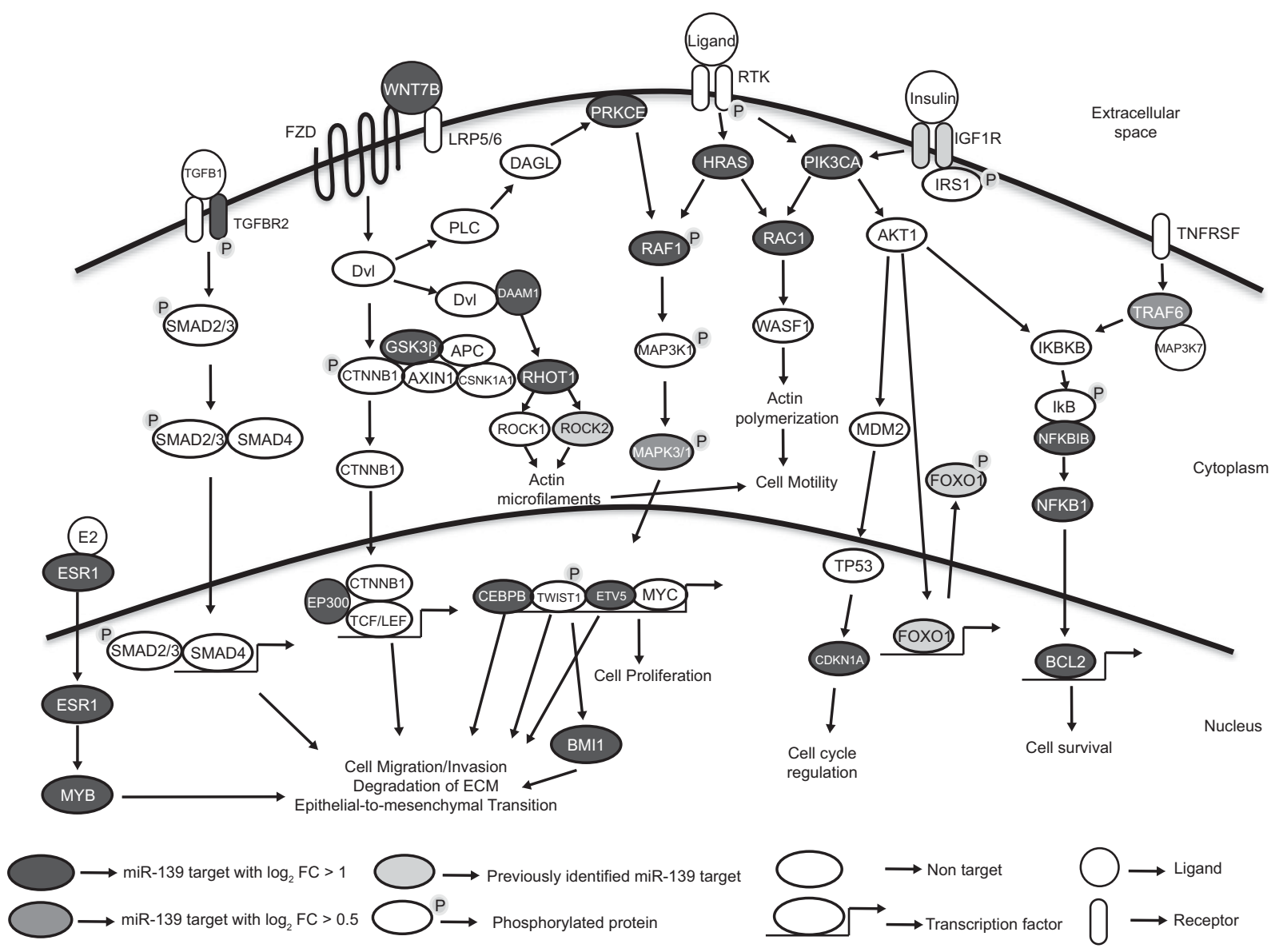

FIGURE 3. Overview of biotinylated miR-139-5p pull-down predicted targets involved in breast cancer invasion and metastasis. Illustration of major pathways being altered by miR-139-5p and the specific components that are targeted. These major pathways, TGF $\beta$, Wnt, and RTK-induced MAPK and PI3K all play a major role in the process of metastasis. Several components within each of these pathways are targeted by miR-139-5p in our pulldowns with $\log _{2} \mathrm{FC}>1$ (dark gray) or $\log _{2} \mathrm{FC}>0.5$ (light gray), or in previously reported studies leading to distinct downstream phenotypes that contribute to the metastatic properties of the cells.

cells (Supplemental Table 4) shows miR-139-5p to be expressed at $\sim 300$ transcripts per million (tpm), where the top $10 \%$ of miRNAs are expressed (miRNAs with $<100$ tpm excluded) with $>1000 \mathrm{tpm}$. The highest expressed miRNA in the cell line had $\sim 74,000 \mathrm{tpm}$ (a difference of $\sim 240$-fold between miR-139-5p and the highest expressed miRNA). This suggested our stable overexpression of miR-139-5p was within physiologically relevant levels. Additionally, an analysis of the data downloaded from The Cancer Genome Atlas (TCGA) that contains data from 893 breast invasive carcinomas and normal patient samples show expression of miRNAs in normal breast tissue to be between $100 \mathrm{tpm}$ and 300,000 tpm with the top $10 \%$ of miRNAs with $>10,000 \mathrm{tpm}$. These findings suggest our levels of expression are within the realms of normal copy numbers per cell. At this low level of overexpression, we did not observe any gross morphological changes or changes in cellular integrity.

All four cell lines were used in the subsequent cell-based assays. We performed MTT assays to measure the rate of proliferation over a time course of four days. Figure $4 \mathrm{~B}$ shows no significant difference in the proliferation rates of the parental (uninduced) cell lines versus the induced cell lines overexpressing miR-139-5p. We also performed FACS analysis of the PI-stained cells to measure any change in the DNA profile of MDA-MB-231 cells in response to miR-139-5p expression. As shown in Figure 4C, there was no statistically significant change in DNA profile. Together, these results suggest that overexpression of miR-139-5p has no effect on cell proliferation or progression through the cell cycle in MDA-MB231 cells. This result also suggests that miR-139-5p may target different gene networks in other cancer types where alterations in proliferation rates have been shown to result from miR-139-5p overexpression.

\section{miR-139-5p suppresses both invasion and migration in MDA-MB-231 cells}

Cellular migration and invasion are key processes underlying metastasis. To test the hypothesis that miR-139-5p overexpression can suppress these phenotypes in breast 

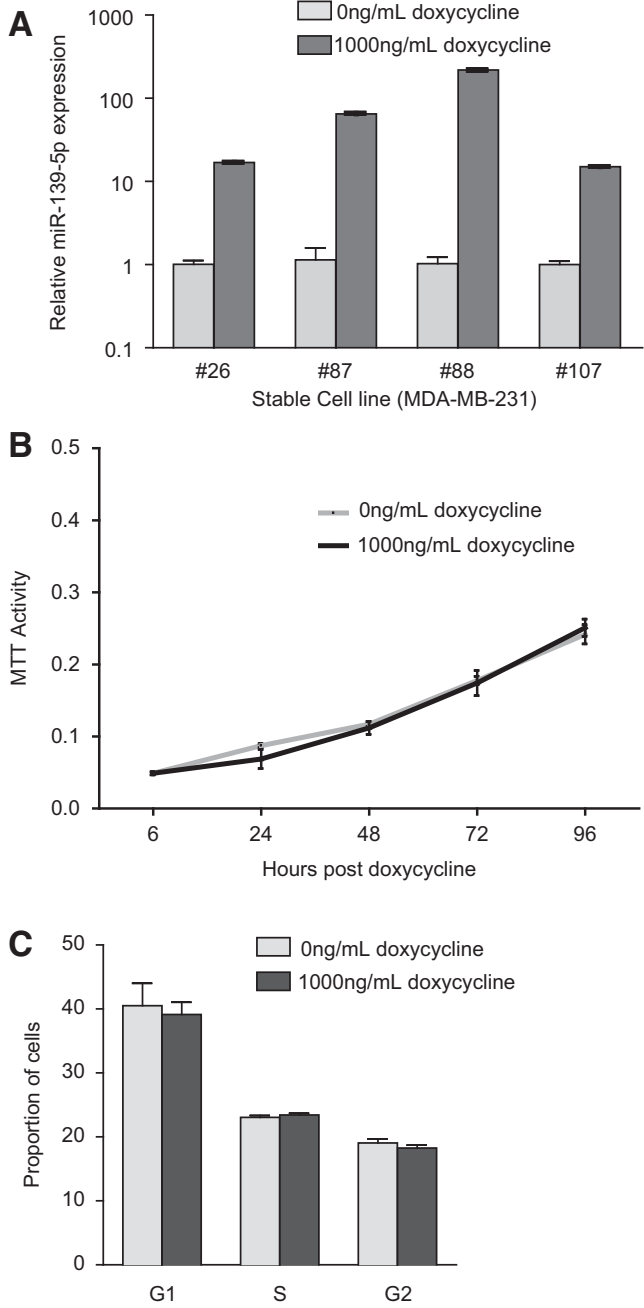

FIGURE 4. Overexpression of miR-139-5p does not induce a proliferative defect. (A) Expression of miR-139-5p as assessed by qRT-PCR in MDA-MB-231 cells (with low endogenous expression of miR-139-5p) stably transfected with miR-139-5p whose expression is induced in response to doxycycline. Four independent cell lines grown in the presence of 0 or $1000 \mathrm{ng} / \mathrm{mL}$ of doxycycline for $48 \mathrm{~h}$ are shown. RNU6B was used as an endogenous control for normalization of expression. (B) MTT cell proliferation assays of MDA-MB-231 cells stably expressing miR-139-5p. The graph plots the mean and SEM of the stable cell lines grown with either 0 or $1000 \mathrm{ng} / \mathrm{mL}$ doxycycline. The induction of miR-139-5p does not affect the proliferation rates of MDA-MB-231 cells. (C) DNA profile analysis of MDA-MB-231 cells stably expressing miR-139-5p. Graph shows the mean and SEM of the percentage of cells in different cell cycle phases, as assessed by FACS. There was no significant difference between MDA-MB-231 cells expressing or not expressing miR-139-5p.

cancer cells, we used the stable cell lines with inducible expression of miR-139-5p in MDA-MB-231 cells. The migratory ability of the stable cell lines was tested by quantifying their ability to traverse a transwell membrane in the presence (1000 ng/mL) or absence of doxycycline. The parent cell line stably expressing an empty vector without the miR$139-5 p$ construct was included in the assay to identify potential side effects of the doxycycline treatment. Cells were plated on the top of a transwell insert containing $8-\mu \mathrm{M}$ pores in basal medium and placed in a well containing medium enriched with EGF. After $6 \mathrm{~h}$, cells that migrated to the bottom of the insert were stained with crystal violet and counted. Induction of miR-139-5p expression, upon addition of doxycycline, significantly decreased the migratory ability of the MDA-MD-231 cells to between $40 \%$ and $70 \%(P<0.05)$ (Fig. 5A,B) of their original levels in the four stable cell lines tested.

The invasive ability of the cells was tested using a similar procedure as outlined above using transwells that contained a layer of matrigel to mimic the basement membrane. Cells were plated on top of the matrigel and invading cells were stained and counted $24 \mathrm{~h}$ after plating. Overexpression of miR-139-5p decreased the ability of the MBA-MB-231 cells to invade to $40 \%-70 \%$ (Fig. $5 \mathrm{C}, \mathrm{D}$ ) of the original levels in all four stable cell lines (reached significance in two of them $[P<0.05])$. These assays reveal a novel role for miR-139-5p in the inhibition of properties that account for the metastatic potential of breast cancer cells. Similar effects of anti-invasive and anti-migratory roles for miR-139-5p have also been shown in other cancer types, like human hepatocellular carcinoma (Wong et al. 2011; Fan et al. 2012) and colorectal cancer cells (Shen et al. 2012).

\section{Validation of miR-139-5p target-binding sites and change in protein expression in MDA-MB-231 cells}

The initial pull-down analysis was performed in MCF7 cells, which is a breast cancer cell line, albeit less invasive than the MDA-MB-231 cells. Since these cells were used in all functional assays, we sought to validate the interaction between miR139-5p and some of the genes enriched in the biotin pulldown using MDA-MB-231 breast cancer cells. The predicted binding sites (and $\sim 60 \mathrm{nt}$ of surrounding sequence) were cloned into the $3^{\prime}$ UTR of the pMIR-REPORT Luciferase construct and transiently transfected into cells. Luciferase activity, indicative of translation from the plasmid, was measured in the presence of a miR-139-5p mimic or negative control mimic and normalized using $\beta$-galactosidase activity. Using this approach, we were able to validate five of seven genes selected (Fig. 6A), including HRAS, NFKB1, PIK3CA, RAF, and RHOT1. These genes are key modulators of the pathways previously discussed (Fig. 3). These data further strengthen our hypothesis that miR-139-5p targets a network of genes underlying cellular processes involved in metastasis. The validation of target binding in the MDA-MB-231 cells also suggests that these targets are possibly the mediators of miR-139-5p's influence on invasion and migration (Fig. 5). The high rate of validation is further evidence of the ability of the biotin pulldown approach to enrich for biologically relevant targets of the miRNA.

We further tested if regulation of these target genes by miR-139-5p could result in observable changes in their protein expression. Western blotting carried out with lysates 


\section{Krishnan et al.}
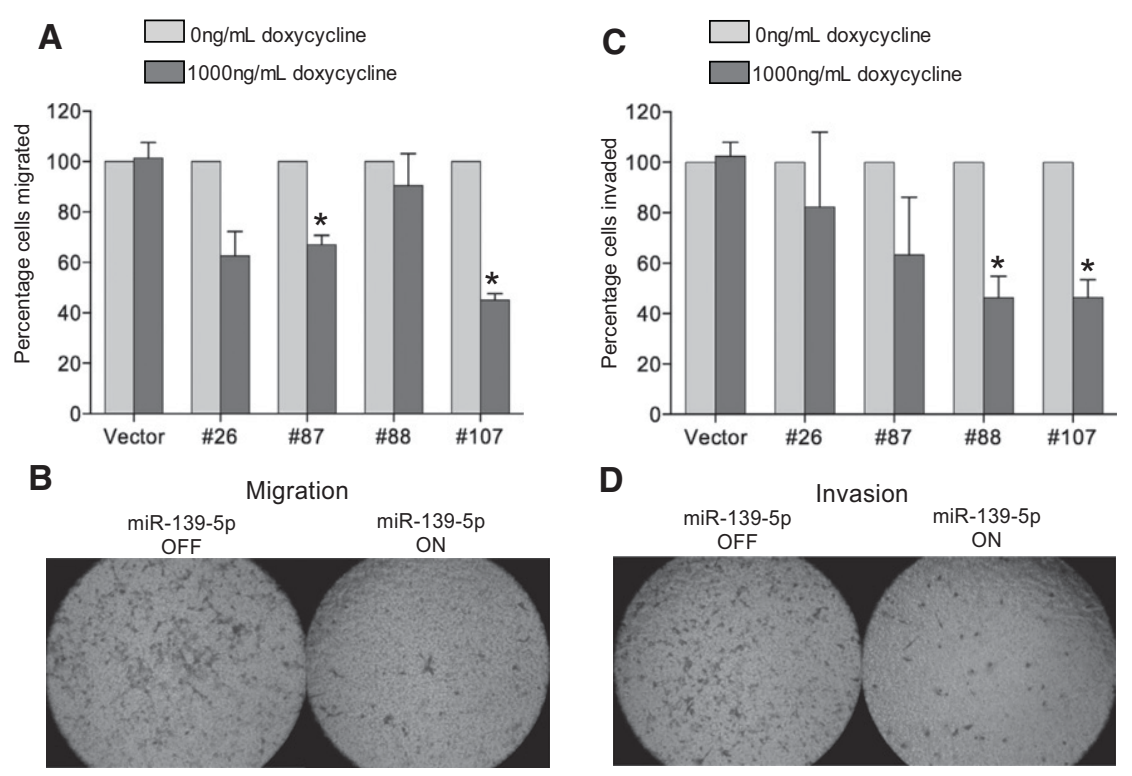

FIGURE 5. The effect of miR-139-5p overexpression on migration and invasion in MDA-MB231 cells. $(A-D)$ MDA-MB-231 cells stably expressing miR-139-5p and empty vector constructs were subjected to Boyden chamber transwell migration and invasion assays as described. Upon doxycycline-inducible ( $1000 \mathrm{ng} / \mathrm{mL})$ expression of miR-139-5p. (A) The ability of the cells to migrate decreased to $40 \%-70 \%$ of the original levels in the stable cell lines. (B) Representative images of migrated cells not expressing miR-139-5p (left) and overexpressing miR-139-5p (right). (C) The ability of the cells to invade through a matrigel basement membrane-like matrix decreased to $40 \%-70 \%$ of original levels in the stable cell lines. $(D)$ Representative images of invaded cells not expressing miR-139-5p (left) and overexpressing miR-139-5p (right). The cell lines stably expressing vector controls did not show significant changes in the invasion or migration assays. These experiments were performed with the vector and four different stable cells lines in triplicate. Data plotted are mean and SEM of three independent biological replicates with at least two technical replicates each. Asterisks indicate $P<0.05$ in a Student's $t$-test.

from stably transfected MDA-MB-231 cells in the presence or absence of doxycycline showed reduction in the protein levels of NFKB1/p50 and PIK3CA and a dramatic loss in the levels of HRAS when miR-139-5p is overexpressed (Fig. 6B,C). Quantification of the levels of protein expression showed statistical significance in the reduction of HRAS and PIK3CA levels across all four stable cell lines, whereas the average $65 \%$ reduction of NFKB1/p50 was not statistically significant when including the increase in protein observed in one cell line. This difference could be attributed to the inherent differences in expression of miR-139-5p across the different stable cell lines and the rate of transcription, which might alter protein levels at different time points. These observations further substantiate our initial findings, showing that miR-139-5p does have a substantial effect on the levels of target genes that are relevant to tumorigenesis, cell migration, and invasion.

\section{DISCUSSION}

In prior studies, miR-139-5p has been shown to have antiinvasive, anti-migratory, and in some cases, anti-proliferative effects on cancer cells. However, studies focusing on its target cohort have been limited to FoxO1 (Hasseine et al. 2009),
Rho-kinase2 (Wong et al. 2011), and c-Fos (Fan et al. 2012) in hepatocellular carcinoma, CXCR4 (Bao et al. 2011) in gastric cancer cells, RAP1B (Guo et al. 2012), and Type I insulin-like growth factor (Shen et al. 2012) in colorectal cancer. In this study, we show miR-139-5p to be associated with human breast cancer, where its expression is frequently downregulated in the more aggressive subtypes. Using the biotin pull-down method, followed by GSEA, we experimentally identified a large cohort of miR-139-5p targets in breast cancer cells, with known functions in pathways underlying the cellular migration and invasion processes. Overexpressing miR-139-5p in MDA-MB-231 cells reduced their invasive and migratory abilities. Together, these findings support the hypothesis that miR-139-5p is a potential anti-metastatic oncomir of solid tumors.

There are certain caveats to be considered when interpreting our results. For instance, although we did not observe gross morphological changes or changes in the cell cycle (Fig. 4B,C), it is possible that the introduction of an exogenous molecule could lead to changes in mRNA expression affecting our ability to detect miRNA targets. Reduced or absence of target expression in the cell line being studied could lead to false negatives, and thus the targets identified in this study should not be considered to be a definitive list of all possible targets in all possible cell types. Similarly, overexpression of an exogenous miRNA (even at the low levels used in this study) could also lead to competition for gene targets with endogenous miRNAs, leading to false positives in our assay. Although we do not observe major disruption to the transcriptional landscape either here or in previous studies (Cloonan et al. 2011; Krishnan et al. 2013), this potential requires that studies of individual miRNA targets will need to be individually validated (Fig. 6). However, the inclusion of a small proportion of false positives is unlikely to affect the functional enrichment analysis performed here (Supplemental Table 3). This style of analyses has shown reliable results with a 0.25 FDR (Subramanian et al. 2005), and for strong biological signals, even a false-positive rate of $50 \%$ can yield accurate results (Cloonan et al. 2008). The accuracy of the analyses in this study is highlighted by our recapitulation of known biological functions for miR-139-5p (Wong et al. 2011; Fan et al. 2012; Shen et al. 2012).

miRNAs achieve specific regulation of cellular processes by concomitant suppression of a network of genes underlying the same function and/or pathways (Cloonan et al. 2008, 

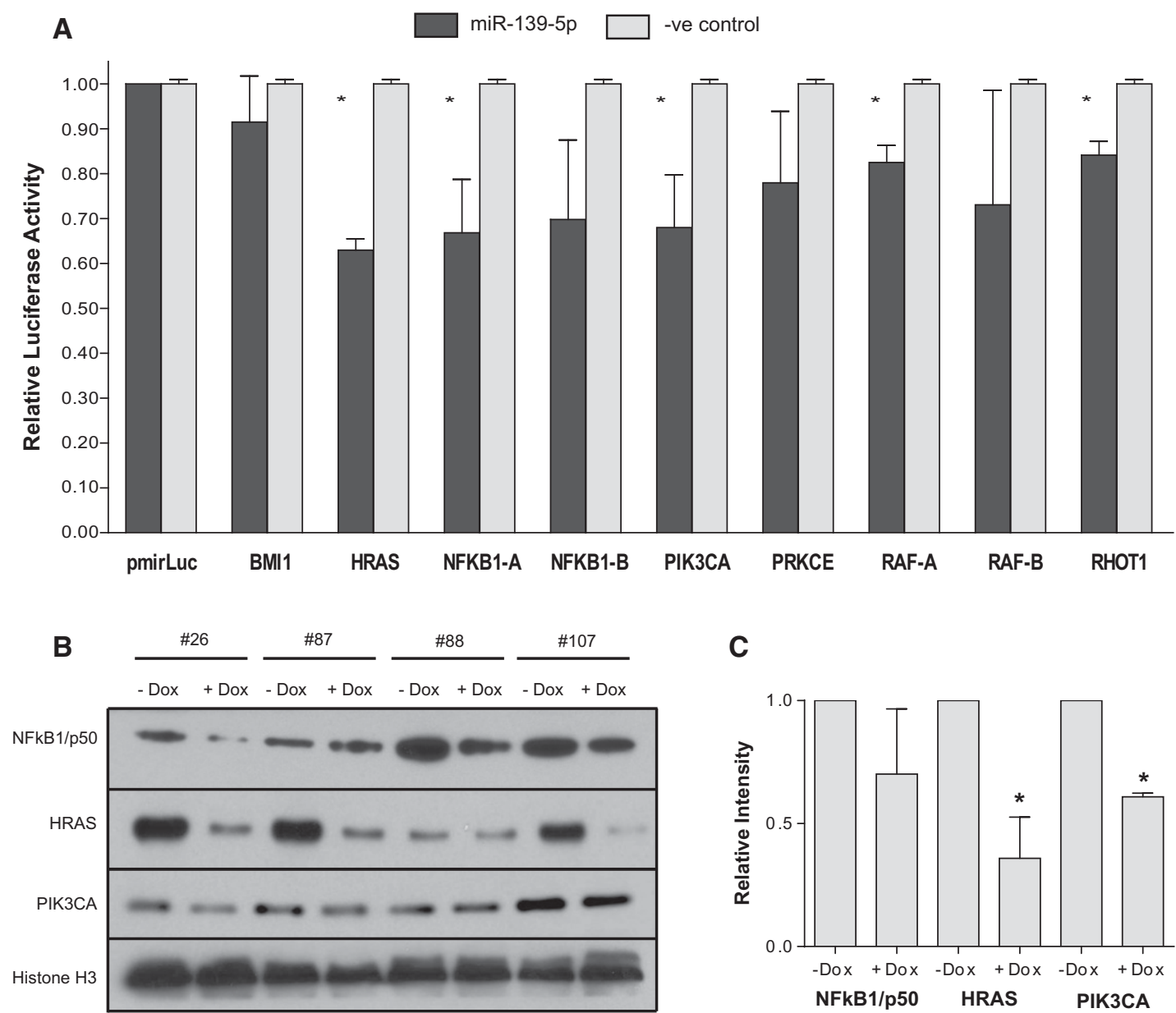

FIGURE 6. Validation of miR-139-5p targets using a luciferase assay and Western blots. (A) MDA-MB-231 cells were transiently cotransfected with $20 \mathrm{nM}$ miR-139-5p or a control mimic with a pMIR-REPORT Luciferase construct containing the predicted binding site from the indicated target gene. Luciferase activity was normalized to $\beta$-galactosidase activity (asterisk indicates $P<0.05$ as indicated in a Student's $t$-test). Data plotted are mean and SEM of at least two independent biological replicates with three technical replicates $(n \geq 2)$. (B) Immunoblotting showing the effects on protein expression of NFKB1/p50, HRAS, and PIK3CA upon induction of miR-139-5p in stably transfected MDA-MB-231 cells. (C) Quantitation of the blots was carried out after normalization to loading control, showing a statistically significant reduction in levels of HRAS and PIK3CA across all stable cell lines. A substantial reduction in NFKB1/p50 was observed in three of four cell lines.

2011; Shirdel et al. 2011; Gennarino et al. 2012). In this study, we have shown miR-139-5p to be able to target several pathways underlying the invasive and migratory phenotypes of cancer cells. The Wnt signaling pathway activation has been shown in several cancers and more specifically in breast cancer (Schlange et al. 2007; Khalil et al. 2012). Schepeler et al. have shown that disruption of Wnt signaling leads to an increase in the levels of miR-139-5p, among other miRNAs, in colorectal carcinoma cells (Schepeler et al. 2012). In our study, we observe components of the Wnt pathway being targets of miR-139-5p. If disruption of Wnt in breast cancer cells also leads to increase in levels of miR-139-5p, it is possible that this miRNA could be part of a regulatory feedback loop that could keep the Wnt pathway in check in normal cells. The invasive and migratory capacity of cells can also be attributed to MAPK signaling, which can occur downstream from PRKC signaling through the Wnt-calcium pathway (Sheldahl et al.
1999) or through RTK-induced downstream Ras and PI3K signaling (Huang et al. 2004; Du et al. 2010).

Through luciferase assays and Western blotting, we were able to confirm Ras and PI3K members to be directly regulated by miR-139-5p, suggesting that the miRNA is likely inhibiting the invasive phenotypes through regulation of RTKmediated downstream signaling. Additionally, NFkB, which can also be regulated by PI3K (Romashkova and Makarov 1999), has been shown to be a direct target of miR-139-5p, which is capable of conferring anti-apoptotic properties on metastatic cancer cells (Buchholz et al. 2005). Ras activates the canonical MAPK pathway (RAF $\rightarrow$ MEK $\rightarrow$ ERK), through which they regulate Rho GTPases, which are key players in cell migration and invasion (Vega and Ridley 2008; Makrodouli et al. 2011). Interaction of PI3K with Rho GTPase members Rac1 and Cdc42 has also been shown to regulate downstream actin reorganization (Tolias et al. 1995) 
and cancer cell migration (Barber and Welch 2006), suggesting that both validated targets of miR-139-5p could be mediating anti-migratory and anti-invasive properties through the same effectors, the Rho GTPases. These properties are classical hallmarks of aggressive breast tumors, suggesting miR-139-5p to be anti-metastatic.

In this study, we show loss of miR-139-5p across the invasive subtypes in three different data sets. However, this loss does not always correlate with other molecular markers usually employed to classify breast cancers, e.g., the triple negative phenotype has been routinely used to classify aggressive breast cancers. More recently, the heterogeneity underlying this subgroup has been noted, warranting more detailed prognostic tools (Metzger-Filho et al. 2012). Consistent with this view, we observe a wide distribution in the expression of miR-139-5p in the triple negative breast cancers analyzed (Fig. 1A). Moreover, analysis of this and the Farazi et al. data sets (Fig. 1A,C) suggests that loss of miR-139-5p could help identify an aggressive subgroup of triple negative cancers. However, a comprehensive screen of a large number of patient samples, including those from relatively rare subtypes, is required to further understand the potential of miR-139-5p as a biomarker for aggressive breast cancer. Experimental validations as performed in this study across

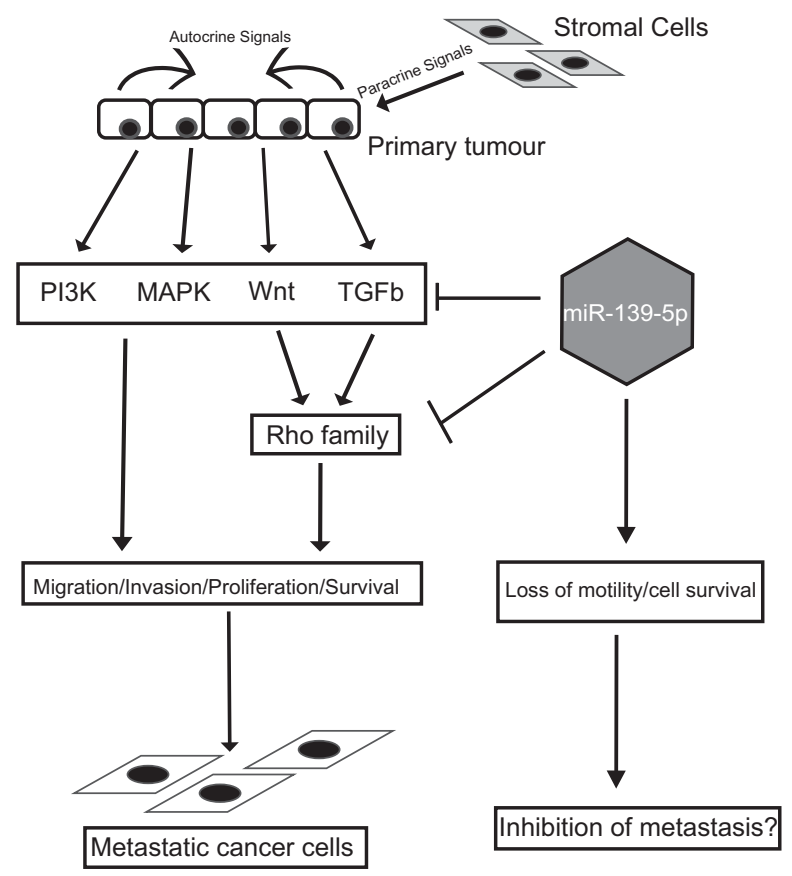

FIGURE 7. Model showing effect of miR-139-5p on tumor progression. Primary tumors, upon receiving autocrine and paracrine signals, respond by downstream activation of key signaling pathways such as TGF- $\beta$, Wnt, MAPK, and PI3K that are responsible for promoting their migratory, invasive, proliferative, and anti-apoptotic properties. Combined acquisition of these phenotypes enables the cells to become metastatic and seed distant organs. Shown in the figure is a potential model where miR-139-5p-mediated inhibition of these pathways can abrogate the onset of metastatic traits, potentially making them more susceptible for currently employed chemotherapeutic regimes. other breast cancer cell lines and subtypes would help to identify its potential as a prognostic marker for the invasive property.

Being widely implicated in the progression of various cancers would indicate a common mode of action by miR-139$5 p$, presumably through the inhibition of signaling pathways underlying the metastatic traits of a wide range of carcinomas (Fig. 7). Metastatic properties of different carcinoma cells have been attributed to the pathways described in this study, among others, suggesting that inhibition of these pathways would be the initial step in reversing the aggressive nature of late stage tumors. Our study now shows experimental evidence for regulation of these pathways by a single miRNA. Future studies in the characterization of these downstream signaling pathways and the mode of miR-139-5p silencing in human cancers would provide further information for its potential use as a therapeutic in the reversal of the metastatic phenotype of breast and other cancers.

\section{MATERIALS AND METHODS}

\section{Cell culture}

MDA-MB-231 cells were maintained in DMEM (Life Technologies Australia) with $10 \%$ FBS and $1 \%$ Pen-strep and grown in a $5 \% \mathrm{CO}_{2}$ atmosphere at $37^{\circ} \mathrm{C}$. MCF7 cells were maintained in similar conditions with the exception of $10 \mu \mathrm{g} / \mathrm{mL}$ bovine insulin (SigmaAldrich) added to the growth media. MDA-MB-231 and MCF7 cell lines were purchased from Cell Bank Australia.

\section{Clinical samples, RNA purification, and qRT-PCR analyses}

Human breast tumors were derived from the Brisbane Breast Bank, collected from consenting patients and with ethical approval from the research ethics committees of The Royal Brisbane \& Women's Hospital and The University of Queensland. Histological type, tumor grade, tumor size, lymph node status, and ER, PR, and HER2 status were obtained from the pathology reports. ER, PR, and HER2 biomarkers were used to infer molecular subtype as luminal, HER2, or triple negative. Total RNA from human tumor samples was extracted using tumor homogenization followed by TRIzol extraction (Invitrogen).

Total RNA was purified from cell lines using the miRNeasy Mini Kit (Qiagen), and RNA integrity was assessed using an Agilent Bioanalyzer 2100. For mature miRNA, cDNA (5-10 ng total RNA) was synthesized using a TaqMan MicroRNA RT Kit (Applied Biosystems), and qRT-PCR was performed using a miR-139-5p MicroRNA TaqMan Assay (Applied Biosystems). All RT-PCR was performed on an Applied Biosystems 7000 SequenceDetection System. For small RNA expression analysis, RNU6B was used as an endogenous control to normalize the data.

\section{Biotin pull-downs, microarray hybridizations}

Pull-downs of miR-139-5p targets were carried out as previously described (Cloonan et al. 2011), using biotin-labeled oligonucleotides 
specific for miR-139-5p (Fig. 2A). Briefly, the 50 pmol of biotinlabeled oligos (IDT) were transiently transfected into MCF7 cells, cultured for $24 \mathrm{~h}$, followed by cell lysis and binding of $50 \mu \mathrm{L}$ myOne C1 Streptavidin Dynabeads (Invitrogen) to the RNA fraction for enrichment. Fifty nanograms of captured mRNA fractions (three independent biological replicates) were amplified and labeled using the Illumina Total Prep RNA Amplification Kit (Ambion) as per the manufacturer's instructions. Samples were profiled on Illumina Human HT-12 chips along with input total RNA from the same cells as negative controls. Microarray data have been deposited to the Gene Expression Omnibus and can be accessed with accession number GSE40411.

\section{Bioinformatic analysis of pulldown microarray data}

Microarray data were normalized using the lumi package (Du et al. 2008) by applying background adjustment, variance-stabilizing transformation (Lin et al. 2008), and robust spline normalization (Workman et al. 2002) successively. The lmFit and eBayes functions in the limma package (Smyth 2004) were used to test differential expression between the pull-down samples and the controls (Cloonan et al. 2011). The false discovery rate was calculated to account for multiple testing (Benjamini and Hochberg 1995). Probes that met the $5 \%$ FDR threshold (for one-sided tests) with a fold-change $>2$ were considered significantly enriched in the pull-down. The transcripts (ENSEMBL V62) to which they matched exactly were considered putative targets of that miRNA. The targets enriched using the biotin pull-downs were analyzed using ingenuity pathway analysis as previously described (Cloonan et al. 2008).

\section{Stable cell line generation}

MDA-MB-231 cells stably expressing miR-139-5p were generated using the Mir-X Inducible miRNA Systems (Clontech). Briefly, MDA-MB-231 cells were transfected with the pTet-on Advanced Vector using Lipofectamine 2000 (Life Technologies Australia, Invitrogen Division), and cells stably expressing the plasmid were selected using $800 \mu \mathrm{g} / \mathrm{mL}$ G418 (Life Technologies Australia) (maintenance concentration: $400 \mu \mathrm{g} / \mathrm{mL}$ G418). Primers (Supplemental Table 5) were used to amplify the miR-139-5p hairpin from human genomic DNA and cloned into the pmRI-Zsgreen vector plasmid supplied and subsequently transfected into the 231-pTet-on parent line. Cells stably expressing the pmRi-Zsgreen-miR-139-5p were selected using $1 \mu \mathrm{g} / \mathrm{mL}$ puromycin and further maintained in $0.5 \mu \mathrm{g} /$ $\mathrm{mL}$ puromycin. Stable expression of miR-139-5p was confirmed using TaqMan MicroRNA Assay (Applied Biosystems) specific for miR-139-5p (Fig. 4A).

\section{MTT proliferation assays}

Stable pmRi-MDA-MB-231 cell lines overexpressing miR-139-5p (1000 ng/mL dox) and parent stables (with no doxycycline) were plated at $1 \times 10^{4}$ cells per well. MTT (3-[4,5-dimethylthiazol-2-yl]2,5-diphenyl tetrazolium bromide) activity was assayed using a Cell Growth Determination Kit (SigmaAldrich) according to the manufacturer's instructions and detected on a PowerWave XS spectrophotometer (BioTek).

\section{Flow cytometry for cell-cycle analysis}

MDA-MB-231 cells stably expressing miR-139-5p were harvested and fixed in $70 \%$ ethanol at $-20^{\circ} \mathrm{C}$ overnight. DNA was stained using $10 \mu \mathrm{g} / \mathrm{mL}$ propidium iodide (SigmaAldrich), and RNA was removed using $200 \mu \mathrm{g} / \mathrm{mL}$ RNase A (SigmaAldrich). Cells were filtered through 35- $\mu \mathrm{m}$ cell strainer mesh (BectonDickinson) and analyzed on a Becton Dickinson LSR II flow cytometer fitted with a 488-nm laser. Cell data were gated and analyzed using FlowJo 7.2.2 (Tree Star).

\section{Cell invasion assay}

MDA-MB-231 cells stably overexpressing miR-139-5p and parent stables (in the presence or absence of doxycycline) were counted and resuspended in serum-free media. Cell were plated at a density of $2 \times 10^{5}$ cells/well in the upper chamber of a matrigel $(200 \mu \mathrm{g})$ coated transwell filter $(8.0-\mu \mathrm{m}$ pore $)$ from Corning. To the reservoir, $650 \mu \mathrm{L}$ of serum-free media with $0.1 \%$ BSA, $1 \%$ tet-FCS, and $10 \mathrm{ng} /$ mL EGF was added. At $24 \mathrm{~h}$, noninvaded cells on the upper side of the matrigel were removed carefully with a cotton swab. The cells bound to the lower side of the filter were washed twice with PBS and fixed with $5 \%$ gluteraldehyde at room temperature for $10 \mathrm{~min}$. Fixed cells were washed twice with PBS and stained using $1 \%$ crystal violet. Excess stain was removed by washing with water, and the filters were dried overnight. Migrated cells were counted in six random fields and images obtained using light microscopy and camera.

\section{Cell migration assay}

MDA-MB-231 cells stably overexpressing miR-139-5p and parent stables (in the presence or absence of doxycycline) were counted and resuspended in serum-free media. Cells were plated at a density of $2 \times 10^{5}$ cells/well in the upper chamber of a transwell filter (8.0$\mu \mathrm{m}$ pore) from Corning. To the reservoir, $650 \mu \mathrm{L}$ of serum-free media with $0.1 \%$ BSA, $1 \%$ tet-FCS, and $10 \mathrm{ng} / \mathrm{mL}$ EGF was added. At $6 \mathrm{~h}$, nonmigrated cells on the upper side of the filter were removed carefully with a cotton swab. The cells bound to the lower side of the filter were washed twice with PBS and fixed with 5\% gluteraldehyde at room temperature for $10 \mathrm{~min}$. Fixed cells were washed twice with PBS and stained using 1\% crystal violet. Excess stain was removed by washing with water, and the filters were dried overnight. Migrated cells were counted in six random fields and images obtained using light microscopy and camera.

\section{Luciferase assay to validate predicted binding sites}

Predicted target sites of miR-139-5p were cloned into the HindIII and SpeI sites of the pMIR-REPORT Luciferase vector. Synthetic oligos (Supplemental Table 5) corresponding to $60 \mathrm{nt}$ surrounding the target sequence were annealed before ligation into the pMIR-REPORT Luciferase vector. All constructs were verified by sequencing. MDA-MB-231 cells were cotransfected with $50 \mathrm{ng}$ of a pMIR-REPORT Luciferase construct and $50 \mathrm{ng}$ of pMIR-REPORT $\beta$-galactosidase Reporter Control Vector (Ambion) along with miR-139-5p or a negative mimic (Ambion) to a final concentration of $20 \mathrm{nM}$. Post-transfection, cells were incubated for $48 \mathrm{~h}$ prior to assaying. Luciferase activity was assayed using the Luciferase Assay System (Promega Corporation) and detected on a Wallac 
1420 luminometer (PerkinElmer). $\beta$-galactosidase activity was determined using the $\beta$-Galactosidase Enzyme Assay System (Promega) and detected on a PowerWave XS spectrophotometer (BioTek). Luciferase activity was normalized to $\beta$-galactosidase activity in each well. Assays were conducted in triplicate and independently repeated at least twice.

\section{Western blotting}

MDA-MB-231 cells stably overexpressing miR-139-5p (in the presence or absence of $1000 \mathrm{ng} / \mathrm{mL}$ doxycycline) grown in $10-\mathrm{cm}$ dishes for $24 \mathrm{~h}$ were washed gently in $5 \mathrm{~mL}$ of ice cold PBS and then lysed using $300 \mu \mathrm{L}$ of ice-cold aqueous lysis buffer (50 mM Tris, $\mathrm{pH}$ 7.5, $150 \mathrm{mM} \mathrm{NaCl}, 10 \mathrm{mM}$ EDTA, $\mathrm{pH}$ 8.0, 0.2\% sodium azide, $50 \mathrm{mM}$ $\mathrm{NaF}, 0.5 \% \mathrm{NP} 40$ ) containing protease (Cat.\# P8340, SigmaAldrich) and phosphatase inhibitors (Cat.\# P5726 and P0044, SigmaAldrich). Lysates were spun at $12,000 \mathrm{~g}$ for $30 \mathrm{~min}$ and the supernatants collected and stored at $-80^{\circ} \mathrm{C}$. Estimation of protein concentration was performed using Bradford reagent (Cat.\# 500-0001, Biorad) using a standard curve created with known concentrations of BSA. Optical density measurements were carried out on an Ultrospec 6300 pro (Amersham Biosciences). Thirty micrograms of protein containing lysate were loaded onto each well of a NuPAGE SDSPAGE gel (Invitrogen) and run for $1.5 \mathrm{~h}$ at $130 \mathrm{~V}$. Protein from the gel was transferred onto PVDF membrane (Millipore) using NuPAGE transfer buffer at 20V for $2 \mathrm{~h}$. Following transfer, membranes were blocked in TBS-T containing 5\% skim milk powder for $1 \mathrm{~h}$ at room temperature, after which they were incubated with primary antibody (1:500)-containing solution (in 5\% BSA) overnight rocking at $4^{\circ} \mathrm{C}$. Primary antibodies used were: rabbit anti-p50/p105 antibody (Cat.\# 3035P, Cell Signaling), rabbit antiHRAS (Cat.\# SC520, Santa Cruz Biotechnology), rabbit antiPIK3CA p110 antibody (Cat.\# 4249S, Cell Signaling), and rabbit anti-histone H3 (Cat.\# 9715, Cell Signaling). Membranes were then washed in TBS-T three times ( 30 min each), followed by incubation with anti-rabbit HRP secondary antibody (Cat.\# 7074, Cell Signaling) at 1:5000 in TBS-T containing 5\% skim milk powder for $1 \mathrm{~h}$ at room temperature. Membranes were then washed in TBS-T and developed using the SuperSignal West Dura Chemiluminescent Substrate (Cat.\# 34076, ThermoScientific) on a Konica Minolta film processor (SRX 201A, Konica Minolta).

\section{DATA DEPOSITION}

Microarray data have been deposited to the Gene Expression Omnibus under accession number GSE40411.

\section{SUPPLEMENTAL MATERIAL}

Supplemental material is available for this article.

\section{ACKNOWLEDGMENTS}

This work was partially supported by an Australian Research Council (ARC) Discovery Project Grant DP1093164. K.K. is supported by an Australian Post Graduate Award (APA), P.T.S. is supported by a fellowship from the National Breast Cancer Foundation, Australia, N.C. is supported by an ARC Future Fellowship (FT 120100453), and S.M.G. is supported by a National Health and Medical Research Council (NHMRC) Principal Research Fellowship. We also thank all the members of QCMG for the helpful discussions and John Pearson, Darrin Taylor, and Scott Wood for HPC infrastructure and support. The authors would also like to acknowledge the contribution of tissue donors and staff for the generation of the Brisbane Breast Bank.

Received August 26, 2013; accepted September 12, 2013.

\section{REFERENCES}

Adriaenssens E, Vanhecke E, Saule P, Mougel A, Page A, Romon R, Nurcombe V, Le Bourhis X, Hondermarck H. 2008. Nerve growth factor is a potential therapeutic target in breast cancer. Cancer Res 68: $346-351$.

Asangani IA, Rasheed SA, Nikolova DA, Leupold JH, Colburn NH, Post S, Allgayer H. 2008. MicroRNA-21 (miR-21) post-transcriptionally downregulates tumor suppressor Pdcd4 and stimulates invasion, intravasation and metastasis in colorectal cancer. Oncogene 27: $2128-2136$.

Aust S, Obrist P, Klimpfinger M, Tucek G, Jager W, Thalhammer T. 2005. Altered expression of the hormone- and xenobiotic-metabolizing sulfotransferase enzymes $1 \mathrm{~A} 2$ and $1 \mathrm{C} 1$ in malignant breast tissue. Int J Oncol 26: 1079-1085.

Bao W, Fu HJ, Xie QS, Wang L, Zhang R, Guo ZY, Zhao J, Meng YL, Ren XL, Wang T, et al. 2011. HER2 interacts with CD44 to up-regulate CXCR4 via epigenetic silencing of microRNA-139 in gastric cancer cells. Gastroenterology 141: 2076-2087 e2076.

Barber MA, Welch HC. 2006. PI3K and RAC signalling in leukocyte and cancer cell migration. Bull Cancer 93: E44-E52.

Benjamini Y, Hochberg Y. 1995. Controlling the false discovery rate: A practical and powerful approach to multiple testing. J R Stat Soc Series B (Methodological) 57: 289-300.

Bentwich I. 2005. Prediction and validation of microRNAs and their targets. FEBS Lett 579: 5904-5910.

Bhowmick NA, Neilson EG, Moses HL. 2004. Stromal fibroblasts in cancer initiation and progression. Nature 432: 332-337.

Blanco MA, Kang Y. 2011. Signaling pathways in breast cancer metastasis-novel insights from functional genomics. Breast Cancer Res 13: 206.

Buchholz TA, Garg AK, Chakravarti N, Aggarwal BB, Esteva FJ, Kuerer HM, Singletary SE, Hortobagyi GN, Pusztai L, Cristofanilli M, et al. 2005. The nuclear transcription factor $\mathrm{\kappa B} / \mathrm{bcl}-2$ pathway correlates with pathologic complete response to doxorubicin-based neoadjuvant chemotherapy in human breast cancer. Clin Cancer Res 11: 8398-8402.

Buck MB, Knabbe C. 2006. TGF- $\beta$ signaling in breast cancer. Ann N Y Acad Sci 1089: 119-126.

Bundy LM, Sealy L. 2003. CCAAT/enhancer binding protein beta $(\mathrm{C} / \mathrm{EBP} \beta)-2$ transforms normal mammary epithelial cells and induces epithelial to mesenchymal transition in culture. Oncogene 22: 869-883.

Cardoso F, Castiglione M. 2009. Locally recurrent or metastatic breast cancer: ESMO clinical recommendations for diagnosis, treatment and follow-up. Ann Oncol 20: 15-18.

Chaudhary A, King WG, Mattaliano MD, Frost JA, Diaz B, Morrison DK, Cobb MH, Marshall MS, Brugge JS. 2000. Phosphatidylinositol 3-kinase regulates Raf1 through Pak phosphorylation of serine 338. Curr Biol 10: 551-554.

Cheang MC, Voduc D, Bajdik C, Leung S, McKinney S, Chia SK, Perou CM, Nielsen TO. 2008. Basal-like breast cancer defined by five biomarkers has superior prognostic value than triple-negative phenotype. Clin Cancer Res 14: 1368-1376.

Clevers H, Nusse R. 2012. Wnt/ $\beta$-catenin signaling and disease. Cell 149: 1192-1205.

Cloonan N, Brown MK, Steptoe AL, Wani S, Chan WL, Forrest AR, Kolle G, Gabrielli B, Grimmond SM. 2008. The miR-17-5p 
microRNA is a key regulator of the G1/S phase cell cycle transition. Genome Biol 9: R127.

Cloonan N, Wani S, Xu Q, Gu J, Lea K, Heater S, Barbacioru C, Steptoe AL, Martin HC, Nourbakhsh E, et al. 2011. MicroRNAs and their isomiRs function cooperatively to target common biological pathways. Genome Biol 12: R126.

Cronan MR, Nakamura K, Johnson NL, Granger DA, Cuevas BD, Wang JG, Mackman N, Scott JE, Dohlman HG, Johnson GL. 2011. Defining MAP3 kinases required for MDA-MB-231 cell tumor growth and metastasis. Oncogene 31: 3889-3900.

Du P, Kibbe WA, Lin SM. 2008. lumi: A pipeline for processing Illumina microarray. Bioinformatics 24: 1547-1548.

Du J, Sun C, Hu Z, Yang Y, Zhu Y, Zheng D, Gu L, Lu X. 2010. Lysophosphatidic acid induces MDA-MB-231 breast cancer cells migration through activation of PI3K/PAK1/ERK signaling. PLoS One 5: e15940.

Fabian MR, Sonenberg N, Filipowicz W. 2010. Regulation of mRNA translation and stability by microRNAs. Annu Rev Biochem 79: 351-379.

Fan Q, He M, Deng X, Wu WK, Zhao L, Tang J, Wen G, Sun X, Liu Y. 2012. Derepression of c-Fos caused by microRNA-139 down-regulation contributes to the metastasis of human hepatocellular carcinoma. Cell Biochem Funct 31: 319-324.

Farazi TA, Horlings HM, Ten Hoeve JJ, Mihailovic A, Halfwerk H, Morozov P, Brown M, Hafner M, Reyal F, van Kouwenhove M, et al. 2011. MicroRNA sequence and expression analysis in breast tumors by deep sequencing. Cancer Res 71: 4443-4453.

Fidler IJ. 2003. The pathogenesis of cancer metastasis: The 'seed and soil' hypothesis revisited. Nat Rev Cancer 3: 453-458.

Gennarino VA, D’Angelo G, Dharmalingam G, Fernandez S, Russolillo G, Sanges R, Mutarelli M, Belcastro V, Ballabio A, Verde P, et al. 2012. Identification of microRNA-regulated gene networks by expression analysis of target genes. Genome Res 22: $1163-1172$.

Gregory PA, Bert AG, Paterson EL, Barry SC, Tsykin A, Farshid G Vadas MA, Khew-Goodall Y, Goodall GJ. 2008. The miR-200 family and miR-205 regulate epithelial to mesenchymal transition by targeting ZEB1 and SIP1. Nat Cell Biol 10: 593-601.

Guo H, Hu X, Ge S, Qian G, Zhang J. 2012. Regulation of RAP1B by miR-139 suppresses human colorectal carcinoma cell proliferation. Int J Biochem Cell Biol 44: 1465-1472.

Hasseine LK, Hinault C, Lebrun P, Gautier N, Paul-Bellon R, Van Obberghen E. 2009. miR-139 impacts FoxO1 action by decreasing FoxO1 protein in mouse hepatocytes. Biochem Biophys Res Commun 390: $1278-1282$

Hirata H, Ueno K, Shahryari V, Tanaka Y, Tabatabai ZL, Hinoda Y, Dahiya R. 2012. Oncogenic miRNA-182-5p targets Smad4 and RECK in human bladder cancer. PLoS One 7: e51056.

Hong J, Zhou J, Fu J, He T, Qin J, Wang L, Liao L, Xu J. 2011. Phosphorylation of serine 68 of Twistl by MAPKs stabilizes Twist1 protein and promotes breast cancer cell invasiveness. Cancer Res 71: 3980-3990.

Huang C, Jacobson K, Schaller MD. 2004. MAP kinases and cell migration. J Cell Sci 117: 4619-4628.

Huntzinger E, Izaurralde E. 2011. Gene silencing by microRNAs: Contributions of translational repression and mRNA decay. Nat Rev Genet 12: 99-110.

Khalil S, Tan GA, Giri DD, Zhou XK, Howe LR. 2012. Activation status of Wnt/ss-catenin signaling in normal and neoplastic breast tissues: Relationship to HER2/neu expression in human and mouse. PLoS One 7: e33421.

Kim J, Shao Y, Kim SY, Kim S, Song HK, Jeon JH, Suh HW, Chung JW, Yoon SR, Kim YS, et al. 2008. Hypoxia-induced IL-18 increases hypoxia-inducible factor- $1 \alpha$ expression through a Rac1-dependent NF$\kappa \mathrm{B}$ pathway. Mol Biol Cell 19: 433-444.

Kim B, Nam HJ, Pyo KE, Jang MJ, Kim IS, Kim D, Boo K, Lee SH, Yoon JB, Baek SH, et al. 2011. Breast cancer metastasis suppressor 1 (BRMS1) is destabilized by the Cul3-SPOP E3 ubiquitin ligase complex. Biochem Biophys Res Commun 415: 720-726.
Korpal M, Lee ES, Hu G, Kang Y. 2008. The miR-200 family inhibits epithelial-mesenchymal transition and cancer cell migration by direct targeting of E-cadherin transcriptional repressors ZEB1 and ZEB2. J Biol Chem 283: 14910-14914.

Korpal M, Ell BJ, Buffa FM, Ibrahim T, Blanco MA, Celia-Terrassa T, Mercatali L, Khan Z, Goodarzi H, Hua Y, et al. 2011. Direct targeting of Sec23a by miR-200s influences cancer cell secretome and promotes metastatic colonization. Nat Med 17: 1101-1108.

Krishnan K, Steptoe AL, Martin HC, Wani S, Nones K, Waddell N, Mariasegaram M, Simpson PT, Lakhani SR, Gabrielli B, et al. 2013. MicroRNA-182-5p targets a network of genes involved in DNA repair. RNA 19: 230-242.

Lau KS, Dennis JW. 2008. N-Glycans in cancer progression. Glycobiology 18: 750-760.

Lee CH, Kuo WH, Lin CC, Oyang YJ, Huang HC, Juan HF. 2013. MicroRNA-regulated protein-protein interaction networks and their functions in breast cancer. Int J Mol Sci 14: 11560-11606.

Li RY, Chen LC, Zhang HY, Du WZ, Feng Y, Wang HB, Wen JQ, Liu X, Li XF, Sun Y, et al. 2013. MiR-139 inhibits Mcl-1 expression and potentiates TMZ-induced apoptosis in glioma. CNS Neurosci Ther 19: 477-483.

Lin SM, Du P, Huber W, Kibbe WA. 2008. Model-based variance-stabilizing transformation for Illumina microarray data. Nucleic Acids Res 36: e11.

Liu Z, Liu J, Segura MF, Shao C, Lee P, Gong Y, Hernando E, Wei JJ. 2012. MiR-182 overexpression in tumourigenesis of high-grade serous ovarian carcinoma. J Pathol 228: 204-215.

Ma L, Teruya-Feldstein J, Weinberg RA. 2007. Tumour invasion and metastasis initiated by microRNA-10b in breast cancer. Nature 449: 682-688.

Ma Y, Zhang P, Wang F, Zhang H, Yang Y, Shi C, Xia Y, Peng J, Liu W, Yang Z, et al. 2012. Elevated oncofoetal miR-17-5p expression regulates colorectal cancer progression by repressing its target gene P130. Nat Commun 3: 1291.

Maeda K, Chung YS, Onoda N, Ogawa M, Kato Y, Nitta A, Arimoto Y, Kondo Y, Arakawa T, Sowa M. 1996. Association of tumor cell proliferation with lymph node metastasis in early gastric cancer. Oncology 53: 1-5.

Makrodouli E, Oikonomou E, Koc M, Andera L, Sasazuki T, Shirasawa S, Pintzas A. 2011. BRAF and RAS oncogenes regulate Rho GTPase pathways to mediate migration and invasion properties in human colon cancer cells: A comparative study. Mol Cancer 10: 118 .

Marchio C, Weigelt B, Reis-Filho JS. 2010. Adenoid cystic carcinomas of the breast and salivary glands (or 'The strange case of Dr Jekyll and Mr Hyde' of exocrine gland carcinomas). J Clin Pathol 63: 220-228.

Maroni P, Bendinelli P, Matteucci E, Desiderio MA. 2007. HGF induces CXCR4 and CXCL12-mediated tumor invasion through Ets1 and NF-кB. Carcinogenesis 28: 267-279.

Mascaux C, Laes JF, Anthoine G, Haller A, Ninane V, Burny A, Sculier JP. 2009. Evolution of microRNA expression during human bronchial squamous carcinogenesis. Eur Respir J 33: 352-359.

Matsuda T, Yamamoto T, Muraguchi A, Saatcioglu F. 2001. Cross-talk between transforming growth factor- $\beta$ and estrogen receptor signaling through Smad3. J Biol Chem 276: 42908-42914.

Metzger-Filho O, Tutt A, de Azambuja E, Saini KS, Viale G, Loi S, Bradbury I, Bliss JM, Azim HA Jr, Ellis P, et al. 2012. Dissecting the heterogeneity of triple-negative breast cancer. J Clin Oncol 30: 1879-1887.

Moutsatsou P, Papavassiliou AG. 2008. The glucocorticoid receptor signalling in breast cancer. J Cell Mol Med 12: 145-163.

Naushad SM, Reddy CA, Rupasree Y, Pavani A, Digumarti RR, Gottumukkala SR, Kuppusamy P, Kutala VK. 2011. Cross-talk between one-carbon metabolism and xenobiotic metabolism: Implications on oxidative DNA damage and susceptibility to breast cancer. Cell Biochem Biophys 61: 715-723.

Padua D, Zhang XH, Wang Q, Nadal C, Gerald WL, Gomis RR, Massague J. 2008. TGF $\beta$ primes breast tumors for lung metastasis seeding through angiopoietin-like 4. Cell 133: 66-77. 
Panizo-Santos A, Sola I, Vega F, de Alava E, Lozano MD, Idoate MA, Pardo-Mindan J. 2000. Predicting metastatic risk of gastrointestinal stromal tumors: Role of cell proliferation and cell cycle regulatory proteins. Int J Surg Pathol 8: 133-144.

Park HS, Park S, Kim JH, Lee JH, Choi SY, Park BW, Lee KS. 2010. Clinicopathologic features and outcomes of metaplastic breast carcinoma: Comparison with invasive ductal carcinoma of the breast. Yonsei Med J 51: 864-869.

Previdi S, Maroni P, Matteucci E, Broggini M, Bendinelli P, Desiderio MA. 2010. Interaction between human-breast cancer metastasis and bone microenvironment through activated hepatocyte growth factor/Met and $\beta$-catenin/Wnt pathways. Eur $J$ Cancer 46: $1679-1691$.

Ramsay AK, McCracken SR, Soofi M, Fleming J, Yu AX, Ahmad I, Morland R, Machesky L, Nixon C, Edwards DR, et al. 2011. ERK5 signalling in prostate cancer promotes an invasive phenotype. $\mathrm{Br} \mathrm{J}$ Cancer 104: 664-672.

Ridolfi RL, Rosen PP, Port A, Kinne D, Mike V. 1977. Medullary carcinoma of the breast: A clinicopathologic study with 10 year followup. Cancer 40: 1365-1385.

Romashkova JA, Makarov SS. 1999. NF-кB is a target of AKT in antiapoptotic PDGF signalling. Nature 401: 86-90.

Romero-Cordoba S, Rodriguez-Cuevas S, Rebollar-Vega R, QuintanarJurado V, Maffuz-Aziz A, Jimenez-Sanchez G, Bautista-Pina V, Arellano-Llamas R, Hidalgo-Miranda A. 2012. Identification and pathway analysis of microRNAs with no previous involvement in breast cancer. PLoS One 7: e31904.

Scheel C, Eaton EN, Li SH, Chaffer CL, Reinhardt F, Kah KJ, Bell G, Guo W, Rubin J, Richardson AL, et al. 2011. Paracrine and autocrine signals induce and maintain mesenchymal and stem cell states in the breast. Cell 145: 926-940.

Schepeler T, Holm A, Halvey P, Nordentoft I, Lamy P, Riising EM, Christensen LL, Thorsen K, Liebler DC, Helin K, et al. 2012. Attenuation of the $\beta$-catenin/TCF4 complex in colorectal cancer cells induces several growth-suppressive microRNAs that target cancer promoting genes. Oncogene 31: 2750-2760.

Schlange T, Matsuda Y, Lienhard S, Huber A, Hynes NE. 2007. Autocrine WNT signaling contributes to breast cancer cell proliferation via the canonical WNT pathway and EGFR transactivation. Breast Cancer Res 9: R63.

Schlessinger K, Hall A, Tolwinski N. 2009. Wnt signaling pathways meet Rho GTPases. Genes Dev 23: 265-277.

Shan SW, Fang L, Shatseva T, Rutnam ZJ, Yang X, Du W, Lu WY, Xuan JW, Deng Z, Yang BB. 2013. Mature miR-17-5p and passenger miR-17-3p induce hepatocellular carcinoma by targeting PTEN, GalNT7 and vimentin in different signal pathways. J Cell Sci 126: $1517-1530$.

Sheldahl LC, Park M, Malbon CC, Moon RT. 1999. Protein kinase C is differentially stimulated by Wnt and Frizzled homologs in a Gprotein-dependent manner. Curr Biol 9: 695-698.

Shen K, Liang Q, Xu K, Cui D, Jiang L, Yin P, Lu Y, Li Q, Liu J. 2012. MiR-139 inhibits invasion and metastasis of colorectal cancer by targeting the type I insulin-like growth factor receptor. Biochem Pharmacol 84: 320-330.
Shirdel EA, Xie W, Mak TW, Jurisica I. 2011. NAViGaTing the micronome-using multiple microRNA prediction databases to identify signalling pathway-associated microRNAs. PLoS One 6: e17429.

Smirnova T, Zhou ZN, Flinn RJ, Wyckoff J, Boimel PJ, Pozzuto M, Coniglio SJ, Backer JM, Bresnick AR, Condeelis JS, et al. 2012. Phosphoinositide 3-kinase signaling is critical for ErbB3driven breast cancer cell motility and metastasis. Oncogene 31: 706-715.

Smyth GK. 2004. Linear models and empirical Bayes methods for assessing differential expression in microarray experiments. Stat Appl Genet Mol Biol 3: doi: 10.2202/1544-6115.1027.

Sood P, Krek A, Zavolan M, Macino G, Rajewsky N. 2006. Cell-typespecific signatures of microRNAs on target mRNA expression. Proc Natl Acad Sci 103: 2746-2751.

Subramanian A, Tamayo P, Mootha VK, Mukherjee S, Ebert BL, Gillette MA, Paulovich A, Pomeroy SL, Golub TR, Lander ES, et al. 2005. Gene set enrichment analysis: A knowledge-based approach for interpreting genome-wide expression profiles. Proc Natl Acad Sci 102: 15545-15550.

Sun Y, Fang R, Li C, Li L, Li F, Ye X, Chen H. 2010. Hsa-mir-182 suppresses lung tumorigenesis through down regulation of RGS17 expression in vitro. Biochem Biophys Res Commun 396: 501507.

Tolias KF, Cantley LC, Carpenter CL. 1995. Rho family GTPases bind to phosphoinositide kinases. J Biol Chem 270: 17656-17659.

Valastyan S, Reinhardt F, Benaich N, Calogrias D, Szasz AM, Wang ZC, Brock JE, Richardson AL, Weinberg RA. 2009. A pleiotropically acting microRNA, miR-31, inhibits breast cancer metastasis. Cell 137: 1032-1046.

Vega FM, Ridley AJ. 2008. Rho GTPases in cancer cell biology. FEBS Lett 582: 2093-2101.

Wei Q, Li YX, Liu M, Li X, Tang H. 2012. MiR-17-5p targets TP53INP1 and regulates cell proliferation and apoptosis of cervical cancer cells. IUBMB Life 64: 697-704.

Wong CC, Wong CM, Tung EK, Au SL, Lee JM, Poon RT, Man K, Ng IO. 2011. The microRNA miR-139 suppresses metastasis and progression of hepatocellular carcinoma by down-regulating Rhokinase 2. Gastroenterology 140: 322-331.

Workman C, Jensen LJ, Jarmer H, Berka R, Gautier L, Nielser HB, Saxild HH, Nielsen C, Brunak S, Knudsen S. 2002. A new nonlinear normalization method for reducing variability in DNA microarray experiments. Genome Biol 3: doi: 10.1186/gb-2002-3-9research0048.

Xue G, Restuccia DF, Lan Q, Hynx D, Dirnhofer S, Hess D, Ruegg C, Hemmings BA. 2012. Akt/PKB-mediated phosphorylation of Twist 1 promotes tumor metastasis via mediating cross-talk between PI3K/Akt and TGF- $\beta$ signaling axes. Cancer Discov 2: 248-259.

Yerushalmi R, Hayes MM, Gelmon KA. 2009. Breast carcinoma-rare types: Review of the literature. Ann Oncol 20: 1763-1770.

Zavadil J, Bottinger EP. 2005. TGF- $\beta$ and epithelial-to-mesenchymal transitions. Oncogene 24: 5764-5774.

Zhu S, Wu H, Wu F, Nie D, Sheng S, Mo YY. 2008. MicroRNA-21 targets tumor suppressor genes in invasion and metastasis. Cell Res 18: 350-359. 

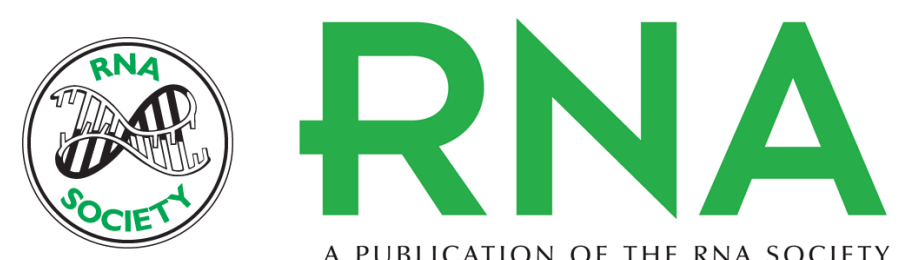

A PUBLICATION OF THE RNA SOCIETY

\section{miR-139-5p is a regulator of metastatic pathways in breast cancer}

Keerthana Krishnan, Anita L. Steptoe, Hilary C. Martin, et al.

RNA 2013 19: 1767-1780 originally published online October 24, 2013

Access the most recent version at doi:10.1261/rna.042143.113

Supplemental Material

References

Open Access

Creative Commons

License

Email Alerting
Service
http://rnajournal.cshlp.org/content/suppl/2013/10/08/rna.042143.113.DC1

This article cites 86 articles, 20 of which can be accessed free at: http://rnajournal.cshlp.org/content/19/12/1767.full.html\#ref-list-1

Freely available online through the RNA Open Access option.

This article, published in $R N A$, is available under a Creative Commons License (Attribution-NonCommercial 3.0 Unported), as described at http://creativecommons.org/licenses/by-nc/3.0/.

Receive free email alerts when new articles cite this article - sign up in the box at the top right corner of the article or click here.

To subscribe to $R N A$ go to:

http://rnajournal.cshlp.org/subscriptions 